not be feared; he points out that, at all events, the average period of stay of the patients was shortened because of the non-occurrence of chronic, insinuating, and acute post-operative infections. $\mathrm{He}$ thinks it doubtless better from every point of view that the cataract patients should wait a few days for the operation rather than that they should be retained in the clinic unduly long after the operation because of subsequent inflammations.

Elschnig points out that if Lindner's investigation leads one to think that the technique of examination employed is not absolutely reliable, it only calls for bettering of the technique, and not for abandoning the method. He concludes the criticism by remarking that a contention as to whether it is worth while knowing the germ-contents of the conjunctival sac before operation, is hardly permissible when one remembers, one must know the dangers in order to avoid them!

D. V. GIRI.

\title{
CORRESPONDENCE
}

\section{VISUAL STANDARDS FOR THE BRITISH ARMY}

\section{To the Editor of The British Journal of Ophthalmology}

SIR,--There is a footnote to the report of the Committee appointed by the Council of the Ophthalmological Society to consider :-- "The standards of vision desirable for the performance of different duties in the British Army" (see January No. of the British Journal of Ophthalmology, page 36), as follows :-

"Some military authorities hold that a man, unless he is a sniper, need not see what he shoots at, only sufficient visual acuity being required, aided if necessary by glasses, to enable him to fire in the right direction. This he can do quite well without accurate aiming, and he can shoot from the right shoulder quite efficiently even if the right eye be blind (cf., Germans who shoot from the right hip during advance). If this view prevailed, a complete revision of standards would be necessary."

From numerous conversations I have had with officers from France, and from information I have obtained by testing the sight of men referred to this Ophthalmic Centre, I should be inclined to think that revision is necessary. A consultation such as the Committee suggest, between ophthalmic specialists and military experts is, I feel sure, highly desirable. But the ophthalmic specialists should be selected from men who have had considerable 
experience in examining the eyes of men who have returned from the front.

The conditions under which war is now carried on have so changed that I believe the standard of vision suggested by the Committee, and which appears to have been adopted by the Army Council, will exclude from A1 a very large number of men. There must be thousands of men whose vision does not reach this standard who have done very good work in the firing line.

Taking one of my case books containing the reports of 650 men who have been at the front. I find there are 22 non-com. officers whose vision in B.E. is $6 / 60$ or less. These must all have done good work to have been granted their "stripes." There is still a larger number whose vision in B.E. is below 6/24. There is, of course, a very much larger number of men whose vision is equally deficient, but who have not got promotion.

To show what can be done I will give particulars of one man, viz. :

Rfn. G.-R.E. $6 / 60$ c. -3 D. cyl. $10^{\circ}=6 / 12$ partly.

L.E. $6 / 24$ partly -4 D. cyl. $160^{\circ}=6 / 9$.

$\mathrm{He}$ is a sniper and first class bomb instructor. He tells me that when sniping he took his glasses off, and could make good practice.

The testing of men's sight by types is very fallacious. The real test of a man's limitations can only satisfactorily be carried out by his instructors. The intelligence of a man has much to do with the amount he can see, and mental amblyopia is not very uncommon.

I would make the following suggestions :-

Men with active disease, and very high myopia, should be rejected.

Men who can see 6/60 with B.E. without glasses should provisionally be placed in A. If the sight can be improved with glasses, these should be ordered, and a report sent to the C.O. as to the condition of the man's sight and his probable limitations.

When the army instructors take them in hand, I believe that in actual practice they will be in a far better position to put them into the proper categories than the ophthalmic specialists.

Yours, etc.,

H. H. TAYLOR, F.R.C.S., Major.

O. i.c. Ophthalmic Centre of the District of Sussex.

\section{ATROPIN IN CATARACT EXTRACTION}

To the Editor BRITISH JouRnal of OpHThalmology

SiR,-In the December number of THE BRITISH Jouknal OF OPHTHALMOLOGY you were good enough to publish a short note 